\title{
Plasma Activated Medium Induces Apoptosis in Chemotherapy-resistant Ovarian Cancer Cells: High Selectivity and Synergy with Carboplatin
}

\author{
Milad Rasouli \\ Kharazmi University
}

Hassan Mehdian ( $\square$ mehdian@khu.ac.ir)

Kharazmi University

Kamal Hajisharifi

Kharazmi University

\section{Elaheh Amini}

Kharazmi University

\section{Kostya Ostrikov}

Queensland University of Technology

\section{Eric Robert}

University of Orléans

\section{Research Article}

Keywords: cold atmospheric pressure plasmas (CAP), oncotherapeutic , A2780 CP and SKOV-3 cells, ovarian cancer

Posted Date: December 22nd, 2020

DOl: https://doi.org/10.21203/rs.3.rs-123386/v1

License: (c) (i) This work is licensed under a Creative Commons Attribution 4.0 International License. Read Full License 


\section{Plasma activated medium induces apoptosis in chemotherapy-resistant ovarian cancer cells: high selectivity and synergy with carboplatin}

Milad Rasouli ${ }^{1}$, Hassan Mehdian ${ }^{1}$, Kamal Hajisharifi ${ }^{1}$, Elaheh Amini' ${ }^{2}$, Kostya (Ken) Ostrikov ${ }^{3}$, and Eric Robert $^{4}$

${ }^{1}$ Institute for Plasma Research and Department of Physics, Kharazmi University, 49 Dr. Mofatteh Avenue, Tehran 15614, Iran. ${ }^{2}$ Department of Animal Biology, Faculty of Biological Science, Kharazmi University, 49 Dr. Mofatteh Avenue, Tehran, Iran. ${ }^{3}$ School of Chemistry and Physics and Institute for Health and Biomedical Innovation, Queensland University of Technology, Brisbane QLD 4000, Australia. ${ }^{4}$ GREMI, UMR 7344, CNRS/Université d'Orléans, 45067 Orléans, France. email: miladrasouli@outlook.com; mehdian@khu.ac.ir)

Abstract: Recently, cold atmospheric pressure plasmas (CAP) have emerged as a promising oncotherapeutic modality, through physical and chemical effects. Here, for the first time, A2780 CP and SKOV-3 cells, relevant to ovarian cancer and GCs as normal ovarian cells were evaluated through CAP directly, indirectly, and concomitant modality of plasma activated medium (PAM) with common drugs to overcome chemotherapy resistance in ovarian cancer. Our results confirm the high potential and the stronger selectivity of PAM in comparison to CAP for the selected cell lines and selectivity mechanism was related to the $\mathrm{pH}$ and concentration of $\mathrm{H}_{2} \mathrm{O}_{2}, \mathrm{NO}_{2}^{-}$, and $\mathrm{NO}_{3}{ }^{-}$ reactive species in the plasma stimulated medium. Compared to the combination of common carboplatin (CAR) and paclitaxel (PTX) chemotherapy treatments, the PAM-based treatment is very promising for ovarian cancer treatment. Our data verify that PAM alone and in combination with carboplatin sensitizes cancer cells to carboplatin, inhibits the SOD1 gene, and selectively induces apoptosis accompanied with high expression of p53, Bax, and activation of Caspase-3. 
Collectively, our observations revealed PAM treatment is an innovative and emerging technology for the future combination or multimodal ovarian cancer oncotherapy.

\section{Introduction:}

Ovarian cancer (OC) is one of the most widespread gynecological malignancies ${ }^{1}$. Carboplatin and paclitaxel are common chemotherapy drugs used for the treatment of ovarian cancer. Resistance to platins and taxanes persists for most patients, rendering them less responsive to further therapy ${ }^{2}$. Any new treatment must have little or no adverse side effects and more effective with high selectivity.

Cold Atmospheric Plasma (CAP) where the temperature of heavy particles except electron is close to room temperature, is generated by feeding a noble gas through a pair of electrodes powered with alternating current $(\mathrm{AC})$ or radiofrequency $(\mathrm{RF})$ signals, typically in the $\mathrm{kV}$ range. The gaseous and liquid phase of CAP contains a mixture of highly reactive oxygen species (ROS) such as superoxide $\left(\mathrm{O}_{2}^{-} \bullet\right)$, hydrogen peroxide $\left(\mathrm{H}_{2} \mathrm{O}_{2}\right)$, hydroxyl radical $(\bullet \mathrm{OH})$, singlet oxygen $\left({ }^{1} \mathrm{O}_{2}\right)$, ozone $\left(\mathrm{O}_{3}\right)$, also reactive nitrogen species $(\mathrm{RNS})$, such as nitric oxide $(\mathrm{NO})$, nitrogen dioxide $\left(\cdot \mathrm{NO}_{2}\right)$, nitrite $\left(\mathrm{NO}_{2}^{-}\right)$, nitrate $\left(\mathrm{NO}_{3}^{-}\right)$, peroxynitrite $\left(\mathrm{ONOO}^{-}\right)$, dichloride radicals $\left(\mathrm{Cl}_{2}{ }^{-}\right)$and hypochloride anions $\left(\mathrm{OCl}^{-}\right)$. Among these long-lived reactive species, hydrogen peroxide, nitrite, nitrate, and peroxynitrite play an important role in the mechanisms of plasma therapy ${ }^{3-12}$.

PAM is a new oncotherapeutics agent and produced using plasma irradiation to the culture medium ${ }^{13}$. Today, CAP and PAM have created new opportunities for cancer treatment. The selective killing of cancer cells without damaging normal cells is the most important feature of these methods. Numerous studies showed that both CAP and PAM have a selective effect toward oral cancer ${ }^{14}$, hepatic cancer ${ }^{15}$, skin cancer ${ }^{16}$, glioblastoma ${ }^{17}$, breast cancer ${ }^{18}$, pancreatic cancer $^{19}$, 


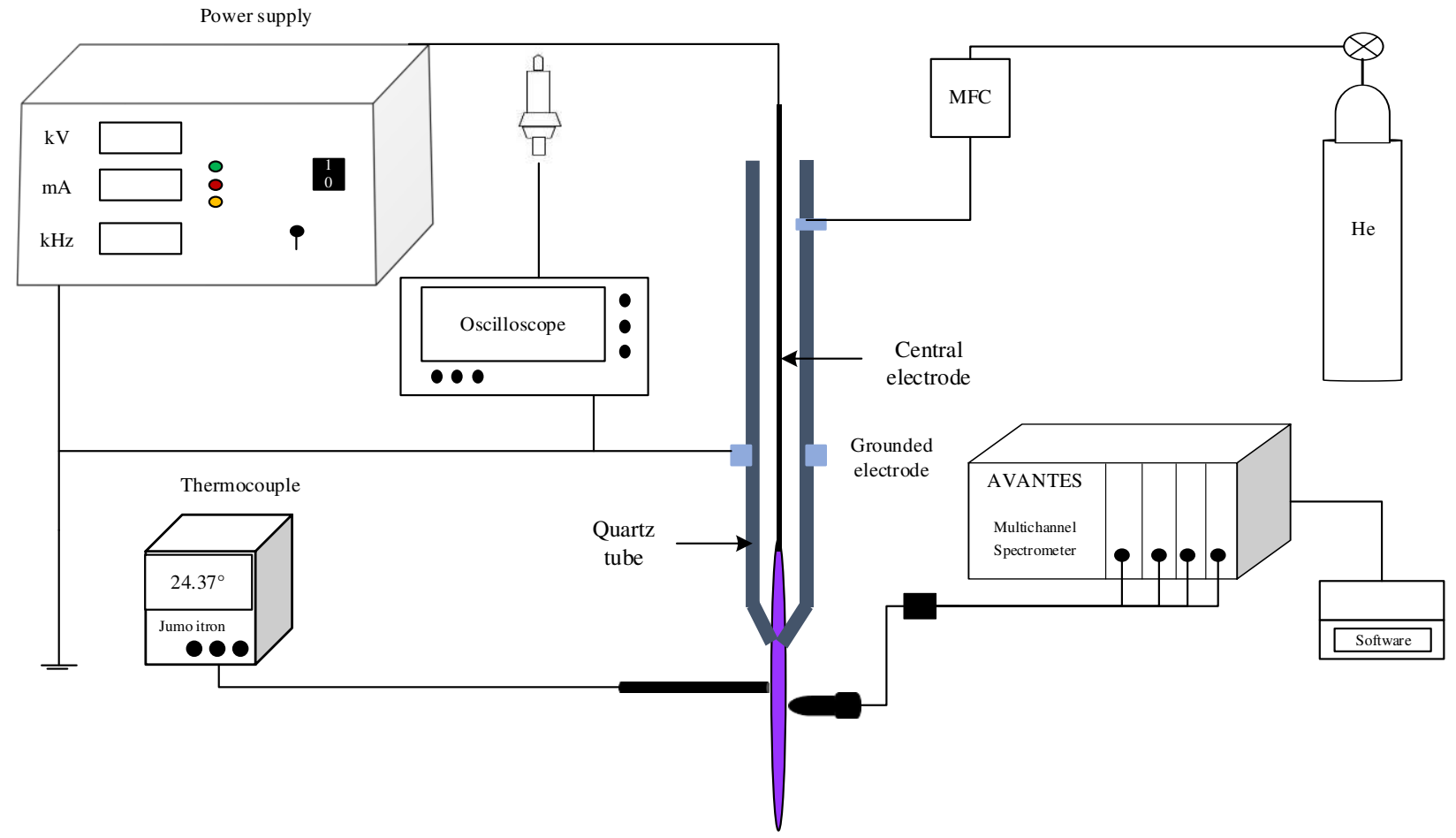

Figure 1. Schematic of the experimental setup

ovarian cancer $^{20}$, neuroblastoma ${ }^{21}$, prostate $\operatorname{cancer}^{22}$, head and neck cancer ${ }^{23}$, lung cancer ${ }^{24}$, osteosarcoma $^{25}$, leukemia ${ }^{26}$, and colorectal cancer $^{27}$ cells.

Here, we examine the therapeutic efficacy of cold atmospheric plasma in two direct and indirect modes on the important challenge of ovarian cancer oncotherapy. Further, we focus on the selective effect of CAP and PAM alone and in conjunction with chemotherapeutic agents on cisplatin-resistant A2780 CP, SKOV-3 cancer cells, and GCs normal cells. To recognize the mechanism underlying components of CAP and PAM, we measured $\mathrm{H}_{2} \mathrm{O}_{2}, \mathrm{NO}_{2}{ }^{-}$, and NO3- as the most important chemical agents. Besides, the biological mechanisms of PAM mediated apoptosis on ovarian cancer cells (A2780 CP, SKOV3) was demonstrated via quantitative real-time reverse transcription-polymerase chain reaction (qRT-PCR). Our data demonstrate PAM is a new and plausible alternative method for chemotherapy-resistance ovarian cancer treatment. 


\begin{tabular}{|c|c|c|c|c|c|}
\hline \multicolumn{5}{|c|}{ IC $_{\mathbf{5 0}}(\boldsymbol{\mu M})$} & Selectivity index (SI) \\
\hline Drugs & $\mathbf{A 2 7 8 0}$ CP & SKOV-3 & GCs & A2780 CP & SKOV-3 \\
\hline PTX (P) & $0.100 \pm 0.036$ & $0.060 \pm 0.018$ & $0.075 \pm 0.014$ & 0.75 & 1.25 \\
\hline PTX (M) & $0.079 \pm 0.011$ & $0.057 \pm 0.010$ & $0.049 \pm 0.013$ & 0.62 & 0.85 \\
\hline CAR (P) & $128.5 \pm 4.34$ & $142.2 \pm 4.00$ & $151.5 \pm 5.672$ & 1.17 & 1.06 \\
\hline CAR (M) & $131.6 \pm 1.30$ & $140.9 \pm 3.56$ & $158.9 \pm 3.40$ & 1.20 & 1.12 \\
\hline
\end{tabular}

Table 1. $\mathrm{IC}_{50}$ Values $(\mu \mathrm{M})$ and Selectivity Index of Cancer Cell Lines Treated With PTX and CAR drugs for 24 h. PTX (P): Paclitaxel diluted in PBS, PTX (M): Paclitaxel diluted in the culture medium, CAR (P): Carboplatin diluted in PBS, CAR (M): Carboplatin diluted in the culture medium.

\section{RESULTS:}

\section{Cytotoxicity and the Selectivity index:}

Table 1 shows the $\mathrm{IC}_{50}$ values and selectivity indices of the CAR and PAM against the selected ovarian cells. For two chemotherapeutic agents, the selectivity indices were smaller than the three that specified for the interesting selectivity index. Also, diagram of used treatment methods demonstrated in Fig. S3.

\section{Selectivity induced of CAP and PAM:}

The experimental setup of the used CAP has been demonstrated in Figure 1. In this study, the selectivity of cold atmospheric plasma was evaluated in the direct $1 \%$ FBS, direct $10 \%$ FBS, PAM $1 \%$ FBS, and PAM 10\% FBS treatment method. In the plasma related treatments, strong selectivity denotes that after the treatment, normal cells have not significantly changed in comparison with untreated cells whereas a significant fraction of cancer cells died ( $\mathrm{p}<0.001)$. Weak selectivity denotes the case when a significant fraction of cancer cells died $(p<0.001)$ while some normal cells also died $(\mathrm{p}<0.05)$. Finally, the condition when the death of normal cells is more pronounced compared to the cancer cells is considered as a negative selectivity. In the direct $1 \% \mathrm{FBS}$, the 
$\mathbf{a}$

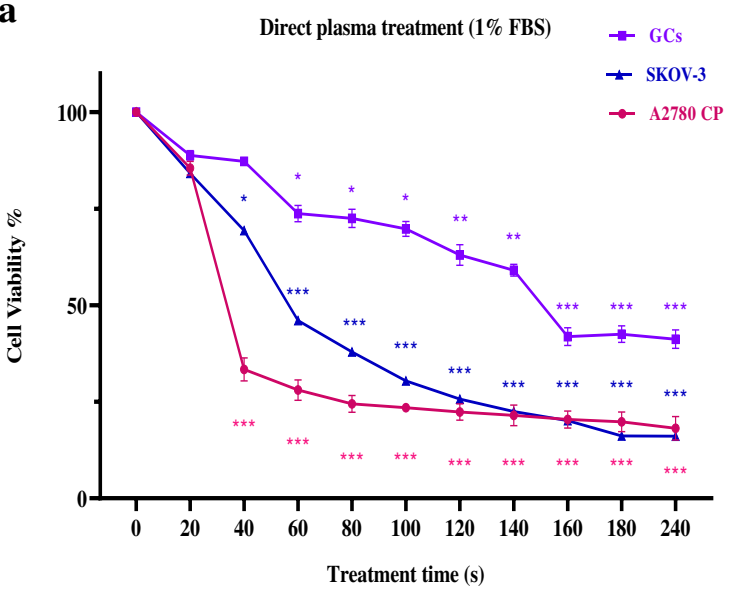

b

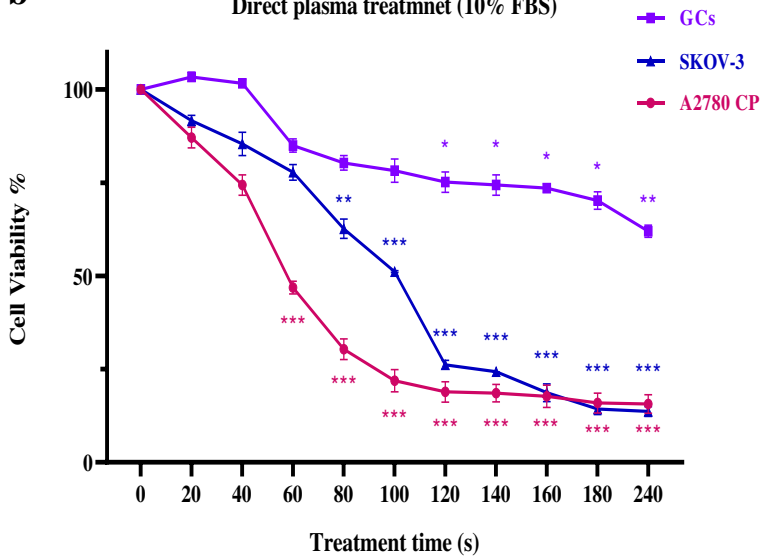

c

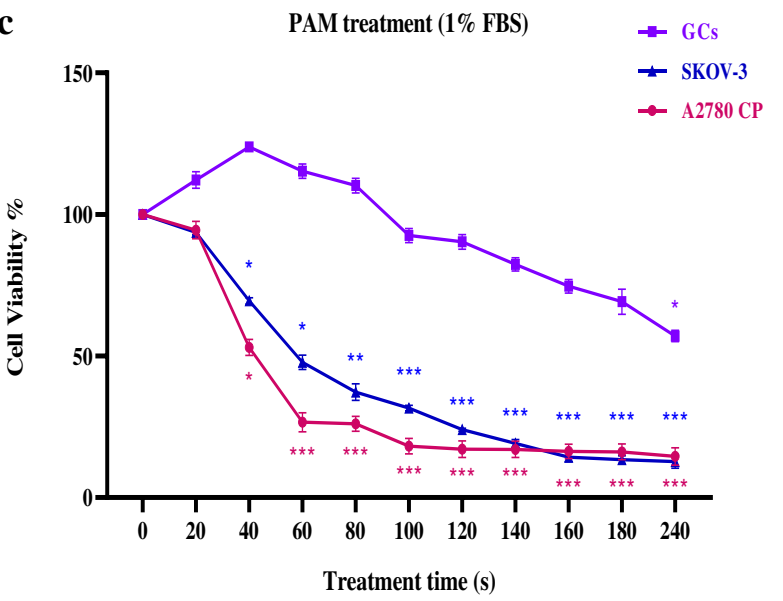

d

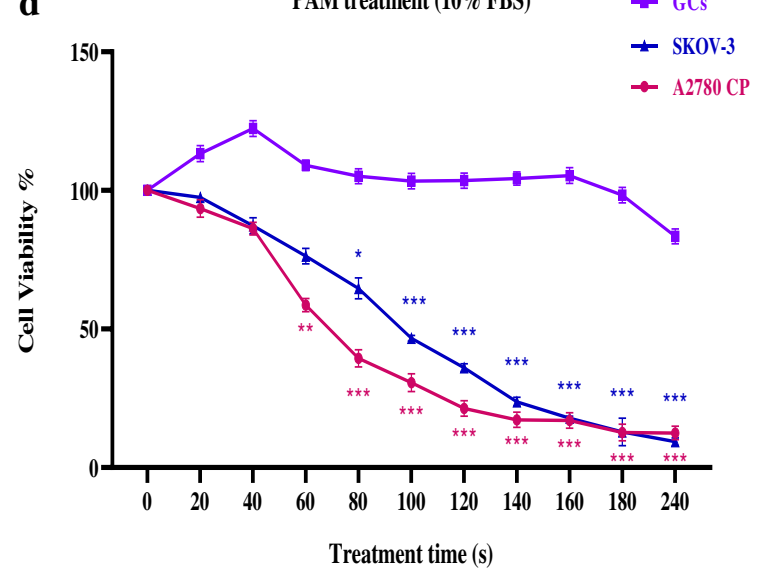

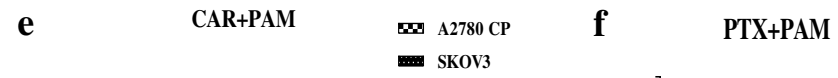
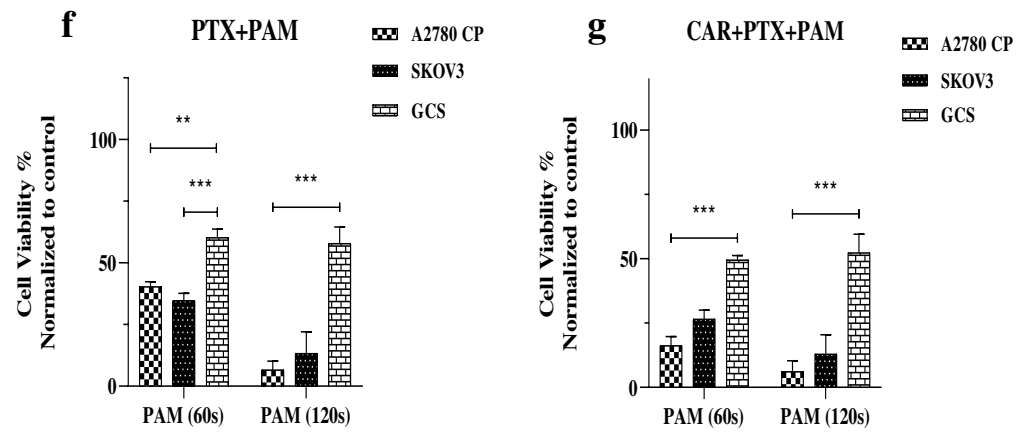

Figure 2. Viability of GCs, SKOV-3, and A2780 CP cells treated with CAP, PAM, and combination of PAM with chemotherapy drugs as measured by the cell viability assay. (a) Direct plasma treatment (1\% FBS). (b) Direct plasma treatment (10\% FBS). (c) PAM treatment (1\% FBS). (d) PAM treatment (10\% FBS). (e) PAM in combination with $0.075 \mu \mathrm{M}$ PTX and $20 \mu \mathrm{M}$ CAR. (f) PAM in combination with 0.075 
$\mu \mathrm{M}$ PTX. (g) PAM in combination with $20 \mu \mathrm{M}$ CAR. The percentages of surviving cells from each cell were calculated relative to controls. All experiments have replicated a minimum of three times. Data are presented as means \pm S.D. $(* \mathrm{p}<0.05, * * \mathrm{p}<0.01, * * * \mathrm{p}<0.001$ versus control).

viability of A2780 CP and SKOV-3 cells decreased to less than 34\% ( $\mathrm{P}<0.001)$ and $69 \%$ (P $<0.01$ ), respectively; whereas normal cells were not affected under $40 \mathrm{~s}$ plasma exposure. This result represents the strong selectivity of the CAP until the $40 \mathrm{~s}$ and weak selectivity until $100 \mathrm{~s}$ plasma exposure. Also, direct 10\% FBS until 100 s plasma treatment time has strong selectivity and normal cells unaffected whereas the viability rate of A2780 CP and SKOV-3 was 21\% (P $<0.001)$ and $51 \%(\mathrm{P}<0.001)$, respectively. It should be pointed out that CAP between $100 \mathrm{~s}$ to 180 $\mathrm{s}$ has a weak selectivity effect towards cancer and normal cells. Besides, PAM $1 \%$ was the other method used to examine the selectivity of CAP. In this method, we observed a strong selective effect until the exposure time of $180 \mathrm{~s}$, so that the percentage of viable cells was reduced $<14 \%$ in cancerous cells, while the viability of normal cells was $69 \%$. In the PAM $10 \%$ FBS, our findings from the MTT experiments indicated that duration of 240s had a non-significant effect on normal cells while the viability of OC cells attenuated to $<10 \%(\mathrm{P}<0.001)$. These results suggest the PAM $10 \%$ FBS with high selectivity is the best alternative method for ovarian cancer therapy (Figure 2).

\section{Synergistic effect of PAM, CAR, and PTX:}

In this section, building upon the results obtained above (e.g., carboplatin inefficiency, the cytotoxic effect of paclitaxel on normal cells, the negative selectivity of the combination of carboplatin and paclitaxel, and selectivity of cold plasma in cancer treatment (Table 1, Figure 2, and Figure S8.)), we investigated the synergistic effects of the mentioned drugs with PAM $10 \%$ FBS, as a new method for cancer treatment. 


\begin{tabular}{|c|c|c|c|c|c|c|c|c|}
\hline \multicolumn{5}{|c|}{ RPMI 1640} & \multicolumn{4}{|c|}{$\alpha$-MEM } \\
\hline \multicolumn{5}{|c|}{$1 \%$ FBS } & \multicolumn{4}{|c|}{$1 \%$ FBS } \\
\hline \multicolumn{5}{|c|}{$10 \%$ FBS } & \multicolumn{4}{|c|}{$10 \%$ FBS } \\
\hline RONS & $1 \mathrm{~min}$ & $2 \min$ & $3 \mathrm{~min}$ & $4 \mathrm{~min}$ & $1 \mathrm{~min}$ & $2 \mathrm{~min}$ & $3 \mathrm{~min}$ & $4 \mathrm{~min}$ \\
\hline $\mathrm{H}_{2} \mathrm{O}_{2}$ & $2.36 \pm .05$ & $5.36 \pm .14$ & $7.23 \pm .08$ & $10.20 \pm .12$ & $1.77 \pm .10$ & $2.57 \pm .05$ & $5.26 \pm .14$ & $10.07 \pm .14$ \\
\hline $\mathrm{H}_{2} \mathrm{O}_{2}$ & $1.60 \pm .09$ & $4.96 \pm .10$ & $7.22 \pm .08$ & $9.57 \pm .14$ & $1.30 \pm .09$ & $2.41 \pm .12$ & $4.86 \pm .13$ & $9.39 \pm .61$ \\
\hline $\mathrm{NO}_{2}^{-}$ & $1.42 \pm .09$ & $2.92 \pm .10$ & $5.87 \pm .07$ & $13.27 \pm .20$ & $0.89 \pm .07$ & $2.33 \pm .13$ & $3.88 \pm .14$ & $6.26 \pm .13$ \\
\hline $\mathrm{NO}_{2}^{-}$ & $2.54 \pm .06$ & $2.74 \pm .04$ & $6.12 \pm .16$ & $12.76 \pm .11$ & $1.19 \pm .12$ & $2.68 \pm .14$ & $4.71 \pm .14$ & $7.01 \pm .15$ \\
\hline $\mathrm{NO}_{3}^{-}$ & $2.46 \pm .23$ & $7.05 \pm .27$ & $17.19 \pm .28$ & $21.29 \pm .23$ & $1.08 \pm .19$ & $3.42 \pm .21$ & $8.75 \pm .28$ & $13.21 \pm .22$ \\
\hline $\mathrm{NO}_{3}^{-}$ & $2.56 \pm .17$ & $7.56 \pm .11$ & $17.80 \pm .26$ & $21.64 \pm .22$ & $0.95 \pm .124$ & $3.61 \pm .16$ & $8.21 \pm .20$ & $13.57 \pm .14$ \\
\hline
\end{tabular}

Table 2. The concentrations of $\mathrm{H}_{2} \mathrm{O}_{2}, \mathrm{NO}_{2}{ }^{-}$, and $\mathrm{NO}_{3}{ }^{-}$in the plasma-activated medium (PAM) for various exposure times

For this purpose, we selected $.075 \mu \mathrm{M}\left(\mathrm{IC}_{50}\right)$ and $20 \mu \mathrm{M}$ doses of PTX and CAR, respectively. We evaluated the synergistic effect of PAM 10\% FBS with CAR and PTX performed in three methods. The results show that, although PAM reduces the cytotoxic effect of PTX on normal cells, the combination of PTX with CAR reduces the viability of normal cells. (Figure. 2.e,f) Our result revealed the combination of CAR and PAM as a promising method, did not reduce the viability of normal cells while cancer cells were affected and the viability of OC cells decreased to $<15 \%$ (P <0.001). Therefore, the combination of PAM and CAR can be further explored as a novel method in ovarian cancer treatment (Figure 2.g).

\section{RONS measurement:}

Due to the importance of RONS in the mechanism of PAM action, after the plasma irradiation, we measured the amount of hydrogen peroxide, nitrate, and nitrite as long-lived species than other produced species. In the first step, the amount of hydrogen peroxide was measured in RPMI-1640 culture medium supplemented with 1\% FBS and 10\% FBS under the plasma irradiation for 1 to 4 min and the results are shown in Table 2. The concentrations of hydrogen peroxide, nitrites, and 
nitrates after 4 min plasma treatment in the culture medium that contains $1 \%$ FBS were 10.20 (mg/l), $13.27(\mathrm{mg} / \mathrm{l})$, and $21.29(\mathrm{mg} / \mathrm{l})$, respectively.

On the other hand, at 10\% FBS recorded $9.56(\mathrm{mg} / \mathrm{l}), 12.76(\mathrm{mg} / \mathrm{l})$, and $21.64(\mathrm{mg} / \mathrm{l})$ concentrations for $\mathrm{H}_{2} \mathrm{O}_{2}, \mathrm{NO}_{2}^{-}$, and $\mathrm{NO}_{3}^{-}$. As shown in Table 2, the amount of $\mathrm{H}_{2} \mathrm{O}_{2}, \mathrm{NO}_{2}^{-}$, and $\mathrm{NO}_{3}{ }^{-}$in $\alpha$-MEM similar to RPMI-1640 depends on the plasma treatment time of the PAM. We detected $10.07(\mathrm{mg} / \mathrm{l}), 6.26(\mathrm{mg} / \mathrm{l})$, and $13.20(\mathrm{mg} / \mathrm{l})$ concentrations for $\mathrm{H}_{2} \mathrm{O}_{2}, \mathrm{NO}_{2}{ }^{-}$, and $\mathrm{NO}_{3}{ }^{-}$at culture medium supplemented with 1\% FBS. For $\alpha$-MEM which contains $10 \%$ FBS, we observed the amounts of $9.39(\mathrm{mg} / \mathrm{l}), 7.01(\mathrm{mg} / \mathrm{l})$, and13.57(mg/l) for $\mathrm{H}_{2} \mathrm{O}_{2}, \mathrm{NO}_{2}{ }^{-}$, and $\mathrm{NO}_{3}{ }^{-}$species, respectively.

\section{Morphological changes:}

After $24 \mathrm{~h}$ of treatment, OC cells stained with $\mathrm{H} \& \mathrm{E}$, and morphological differences between the treated and control cells were observed by an optical microscope (Figure 3).

\section{Acridine orange (AO) \& propidium iodide (PI) staining:}

In the present study, AO/PI is utilized to recognize live, apoptotic, and necrotic cells, which are categorized by their color (green, yellow-green, stained orange and stained red for live, early apoptotic, late apoptotic and necrotic cells, respectively. As shown in Figure 3, normal cells are not affected by the treatment, compared to cancer cells in which apoptosis and necrosis observed. These results confirm the selectivity of the plasma and improvement of this selectivity in synergy with carboplatin.

\section{Analysis of gene expression by real-time PCR}

To clarify the expression of apoptosis related genes (Bax, Caspase 3, P53, and SOD1) for A2780 CP and SKOV-3 cells, we utilized the quantitative real-time PCR (qRT-PCR). In A2780 CP cells, 


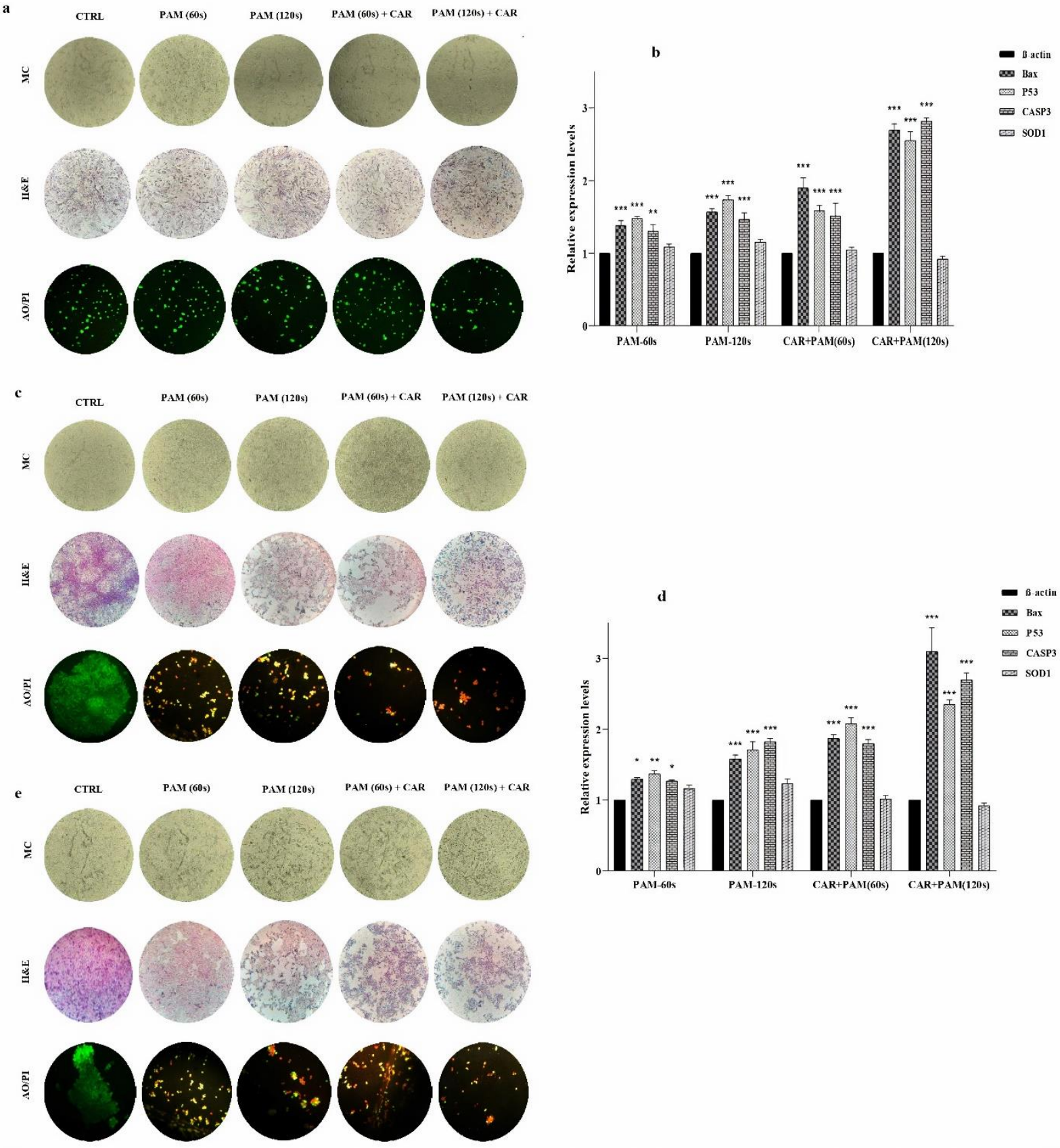

Figure 3. (a) Morphological change, Hematoxylin and Eosin, and acridine orange/propidium iodide staining of GCS cells. (b) RT-PCR quantitation of mRNA levels of Bax, P53, Caspase 3, and SOD1 in A2780 CP cells (c) Morphological change, Hematoxylin and Eosin, and acridine orange/propidium iodide staining of A2780 CP cells, (d) RT-PCR quantitation of mRNA levels of Bax, P53, Caspase 3, and SOD1 in SKOV3 cells. (e) Morphological change, Hematoxylin and Eosin, and acridine orange/propidium iodide 
staining of SKOV-3 cells. actin beta ( $\beta$-actin) was used as control. Data are the mean of at least three different experiments. Data are presented as means \pm S.D. $(* p<0.05, * * p<0.01, * * * p<0.001$ versus control).

as expected of MTT and other tests, a strong increase of both Bax and p53 expression compared to control was measured ( $\mathrm{p}<0.001$ ). Further, the caspase-3 mRNA expression had a noticeable changes (p <0.01), (p<0.001), (p<0.001), ( $<<0.001)$ at PAM (60s), PAM (120s), CAR with PAM (60s), and CAR with PAM (120s), respectively (Fig. 3.b). Furthermore, for SKOV-3 cell lines, in comparison with untreated cells, we detected the overexpression $(\mathrm{p}<0.001)$ for $\mathrm{p} 53$, Bax, and caspase-3 genes at PAM (120s), CAR with PAM (60s), and CAR with PAM (120s), respectively. While in PAM (60s) expression of p53, Bax, and caspase-3 genes were ( $p<0.01),(p<0.05)$, and ( $\mathrm{p}<0.05)$, respectively (Fig. 3.d). Another gene that was evaluated in this study was SOD1, which had a non-significant change in comparison to non-treatment for two cell lines in all treatments (Figure 3.b,d).

\section{Discussion:}

This was the first study of the effect of CAP and PAM alone or in combination with carboplatin and paclitaxel on the A2780 CP and GCs cells. Our results reveal that, while the CAP showed better selectivity than carboplatin and paclitaxel, PAM treatment presented an even stronger selectivity towards OC cells.

Contrary to the previous results suggesting that PAM has similar anti-cancer effects as direct CAP treatment ${ }^{28}$, we conclude that these two methods performed differently. The anti-cancer effect of PAM is based on long-lived reactive oxygen and nitrogen species while, in CAP treatments, in addition to the long-life reactive species, short-life reactive species, and physical effects such as UV radiation, electromagnetic fields, shock waves, and a number of RONS that are still unknown 
also affect the outcomes ${ }^{29}$. It appears that healthy cells are more sensitive than cancer cells to CAP treatment while cancer cells do not show much difference in their response between the CAP and PAM treatments. One possibility is that healthy cells are more sensitive to the mentioned physical factors in comparison to the cancer cells. This is an important finding that PAM has a very strong selectivity performance than CAP because PAM with greater permeability to the depth of tissue, ability to be maintained, the possibility of synergistic and uniform treatment with conventional treatments such as chemotherapy can complement some shortcomings of direct CAP treatment ${ }^{30,31}$.

Another promising finding was regarding the effective role of fetal bovine serum (FBS) in the selectivity of both CAP and PAM treatments. First, increasing FBS reduces the cytotoxic effect of CAP and PAM. This result agrees well with Yan et al. ${ }^{32}$ wherein the FBS had a protective role against the plasma. Second, increasing FBS levels in both CAP and PAM methods is associated with improved selectivity effects. The presence of FBS is associated with an increase in the time required to kill cancer cells but due to its greater protective effect in healthy cells, it can be considered as an important factor in the selectivity process.

Besides, our results revealed the importance of the amount of medium, the time of plasma irradiation, and the amount of FBS present in the medium, the distance between the nozzle and the cell culture plate in the performance process of the PAM treatment. The optimum combination of all these conditions has produced the observed strong selectivity effects.

To understand the role of RONS and $\mathrm{pH}$, we measured the extracellular concentrations of $\mathrm{H}_{2} \mathrm{O}_{2}$, $\mathrm{NO}_{2}{ }^{-}$, and $\mathrm{NO}_{3}{ }^{-}$also $\mathrm{pH}$ in PAM. Our data revealed that the $\mathrm{H}_{2} \mathrm{O}_{2}, \mathrm{NO}_{2}{ }^{-}$, and $\mathrm{NO}_{3}{ }^{-}$concentrations increase with longer plasma exposure. In line with previous studies ${ }^{33}$, our results show that the concentration of $\mathrm{H}_{2} \mathrm{O}_{2}$ in the PAM decreases with $10 \%$ FBS as compared with PAM $1 \%$ FBS, 


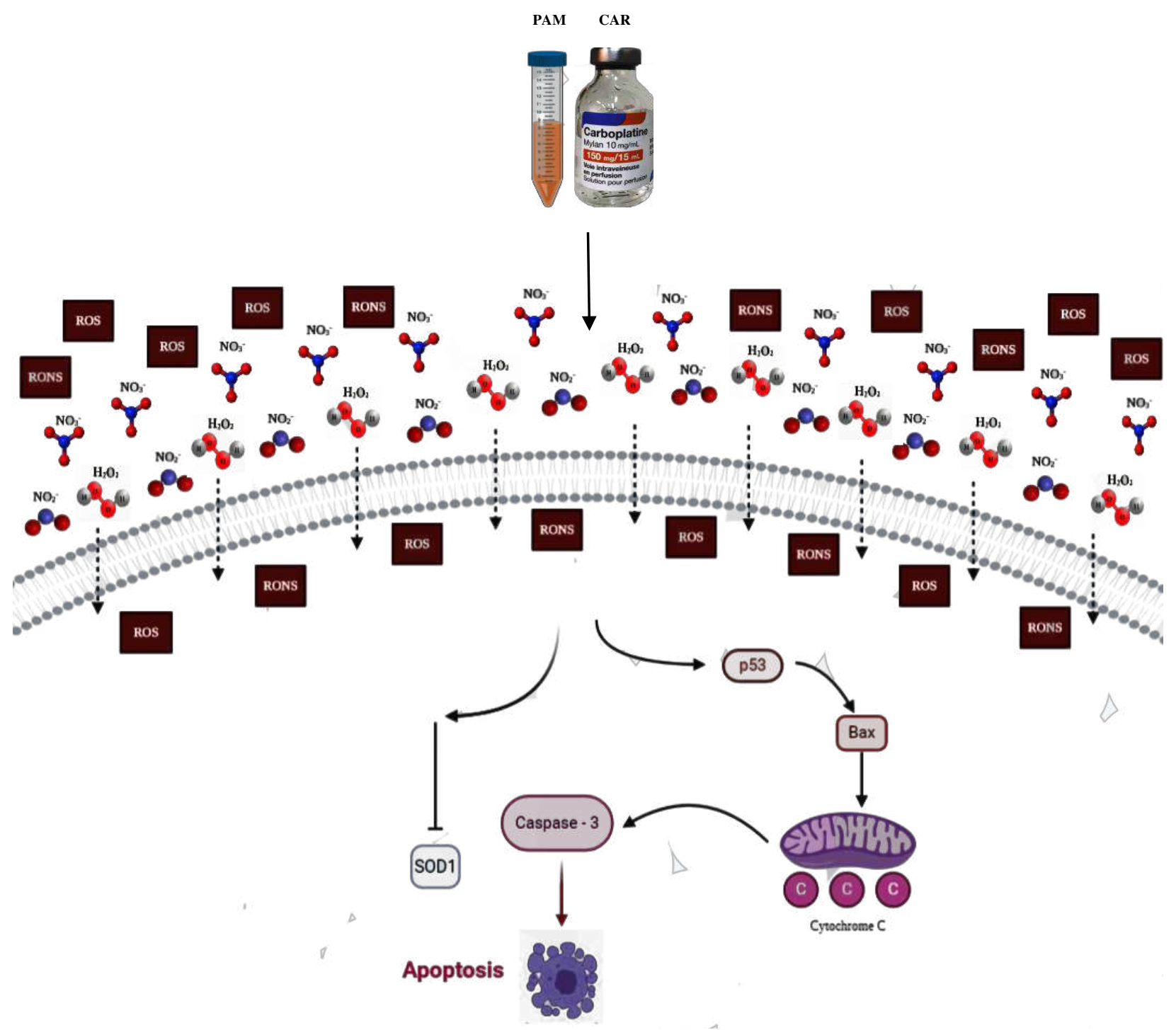

Figure 4. Molecular mechanism of inhibition of the SOD1 and mitochondrial related intrinsic apoptosisinducing by PAM and CAR

whereas the concentration of $\mathrm{NO}_{2}{ }^{-}$and $\mathrm{NO}_{3}{ }^{-}$does not follow a defined pattern with the increase of FBS concentration.

Importantly, $\mathrm{H}_{2} \mathrm{O}_{2}$ may have different applications depending on the concentration. At low-level concentration, it has a physiological role in cell signaling, whereas at high concentration it can cause cell death. Cancer cells also appear to produce a high level of $\mathrm{H}_{2} \mathrm{O}_{2}$ compared to normal 
cells ${ }^{34,35}$. It has been reported that $\mathrm{H}_{2} \mathrm{O}_{2}$ in the range of 0.34 to $2.72 \mathrm{mg} / \mathrm{l}$ cannot induce apoptosis in cancer cells ${ }^{36}$. Therefore, at least in PAM (60 s), $\mathrm{H}_{2} \mathrm{O}_{2}$ can not be considered the only cause of selective apoptosis without $\mathrm{NO}_{2}^{-}$. Besides, since the concentrations of $\mathrm{H}_{2} \mathrm{O}_{2}$ detected in the PAM did not change significantly for either culture medium, we conclude that the effect of $\mathrm{H}_{2} \mathrm{O}_{2}$ on cells depends on the cell type so that cancer cells are more vulnerable than normal cells. In short, despite its important role of $\mathrm{H}_{2} \mathrm{O}_{2}$, it is not the only cause for the selective effect of PAM in cancer treatment.

Hence, we consider the synergistic effect of $\mathrm{H}_{2} \mathrm{O}_{2}$ and $\mathrm{NO}_{2}{ }^{-}$to play a role in the selective effect of PAM. Several other researchers also emphasized the synergistic interaction of $\mathrm{H}_{2} \mathrm{O}_{2}$ and $\mathrm{NO}_{2}{ }^{-}$ ${ }^{27}$ that it is required for selective apoptosis induction in tumor cells as well as the production of peroxynitrite and primary oxygen singlet ${ }^{3,33}$. This study confirmed that $\mathrm{pH}$ of the culture medium decreased after the plasma exposure ${ }^{37}$. Indeed, the $\mathrm{pH}$ of the two culture media decreased after 4 min of the plasma exposure. Our findings on the simultaneous effect of $\mathrm{H}_{2} \mathrm{O}_{2}$ and $\mathrm{NO}_{2}{ }^{-}$and also, the acidification of our culture medium which is the basic factor to produce primary and secondary ${ }^{1} \mathrm{O}_{2}$, are consistent with the selectivity mechanism of Bauer et al. ${ }^{3,7}$

During this study, we investigated the action of p53 among tumor suppressor genes. In ovarian cancer cells, p53 is a crucial apoptotic cell death mediator ${ }^{38}$. Mechanisms of apoptosis induction by p53 have been identified in prior studies. One of these mechanisms is that p53 induces apoptosis by transcriptional up-regulation of proapoptotic genes such as Bax. Bax is classified as proapoptosis and a member of the Bcl-2 family proteins which are critical regulators of apoptosis. Caspase-3 is part of the family of cysteine proteases that cleave certain vital structural proteins and proteolytically activate latent enzymes that contribute to cell apoptosis ${ }^{39,40}$. From these points, the results of this study demonstrate that the PAM with the mechanism presented in the previous 
section causes the increased expression of p53, Bax, and Caspase-3 genes, inhibit proliferation and induces p53-dependent mitochondrial apoptosis in A2780 CP and SKOV-3 cells (Figure 4.). The findings are directly in line with the previous studies which suggested that CAP and PAM induce apoptosis in cancer cells through the mitochondrial pathway ${ }^{41,42}$.

SOD1 known as $\mathrm{Cu} / \mathrm{Zn}$ SOD plays a vital role in converting superoxide into $\mathrm{H}_{2} \mathrm{O}_{2}$. The overexpression of SOD1 causes resistance to chemotherapy in cancer cells. Besides, prior works showed that inhibition of SOD1 can be used to enhance cancer cell death ${ }^{43,44}$. In line with the previous study ${ }^{20}$ our results demonstrated that after PAM and combination treatments, the expression of the SOD1 does not change significantly. These findings cast a new light on ovarian cancer treatment by inhibition of SOD1 with an application of CAP.

The next part of this study was the study of the effect of PAM with CAR and PTX. In this regard, these drugs were investigated alone and together with PAM. We stress that A2780 CP and SKOV3 cells are also resistant to carboplatin. Also, CAR did not have a significant cytotoxic effect on selected cells and these cells remained unaffected under the doses that are commonly used in clinical trials. On the other hand, we observed that PTX alone and in the combination with CAR showed negative selectivity so that normal GCs cells are more affected than cancerous cells. Therefore, this treatment method re-sensitized A2780 CP and SKOV-3 to CAR and induced selective apoptosis in cancer cells.

CAP helps reduce the resistance of cancer cells to chemotherapy drugs ${ }^{45}$, e.g., TRAIL-resistant colorectal cancer cells ${ }^{46}$. Here we examined one of the most important resistance mechanics. We found that all of the combination treatments with PAM restore carboplatin sensitivity in resistant A2780 CP and SKOV-3 ovarian cancer cells. However, only the synergy of PAM and CAR restored carboplatin sensitivity, targeted cancer cells, and left normal cells unscathed. 
Another promising finding was that the combination of CAR and PAM affects apoptosis regulation as discussed above. Consequently, ovarian cancer cells, A2780 CP, and SKOV-3, which were resistant to carboplatin, follow mitochondrial pathways of apoptosis if treated synergistically with PAM.

Collectively, our strategy to target the resistance mechanisms, in particular reducing the absorption of carboplatin into the tumor and inhibiting apoptosis, was the simultaneous combination of PAM and carboplatin. The mechanism of action of PAM and carboplatin can be attributed to several factors. The first factor is the penetration of carboplatin into the tumor due to the effect of plasma on reducing the $\mathrm{pH}$ of the culture medium. Lower $\mathrm{pH}$ causes more carboplatin to penetrate the tumor ${ }^{47}$. The other factor is the production of RONS $\left(\mathrm{H}_{2} \mathrm{O}_{2}, \mathrm{NO}_{2}{ }^{-}\right)$by CAP in culture media. Another possibility, yet to be confirmed, is the activation of sphingolipids and ceramide production which is a promising strategy for overcoming drug resistance ${ }^{48}$.

\section{CONCLUSION:}

To our knowledge, this is the first report that investigates the effect of CAP and PAM on A2780 CP and GCs ovarian cells. This is important because A2780 CP and SKOV-3 cells are highlyresistant to carboplatin used in common chemotherapy treatments. Overall, our results demonstrate a high and selective lethal effect of CAP and PAM on two ovarian cancer cells. Besides, physical and chemical factors have an important role in the anti-cancer effect of CAP. Our study has confirmed that PAM shows strong selectivity and as such represents an effective alternative for CAP and other common treatments. The combination of $\mathrm{H}_{2} \mathrm{O}_{2}$ and $\mathrm{NO}_{2}^{-}$plays a central role in initiating the selectivity of PAM. PAM with up-regulation of p53, Bax, and caspase-3 induce mitochondrial-dependent apoptosis in ovarian cancer cells. Importantly, our results have demonstrated that PAM sensitized CAR resistant ovarian cancer cells to combination (or 
multimodal) CAR based treatments and induce selective apoptosis in the cancer cells. Future research could continue to explore the precise mechanisms of these methods and the exact effect of physical and chemical factors on the selective action of PAM and CAP. Finally, our findings provide a potential method for ovarian cancer treatment using the optimum combinations of CAP or PAM with common chemotherapeutic agents such as CAR.

\section{MATERIAL AND METHODS:}

Ethics statement. All experimental protocols were carried out in accordance with the relevant guidelines and regulations and were discussed and approved by the Research Ethics Committee of Kharazmi University. All animal maintenance and procedures were in accordance with the ARRIVE guidelines and recommendations established by the Iran National Committee for Ethics in Biomedical Research, Research Ethics Committee of Kharazmi University as well as the United States NIH guidelines (publication no. 85-23). The protocols were approved by the Research Ethics Committee of Kharazmi University and conducted under the Project ID (IR.KHU.REC.1399.011). All surgeries were performed under deep anesthesia, and all efforts were made to minimize suffering.

\section{Culture of cell lines and primary GCs cells:}

A2780 CP (human ovarian carcinoma-acquired resistant to cisplatin) cells and SKOV-3 (with intrinsic cisplatin resistance) which is a hypodiploid human cell line, were obtained from Pasteur Institute of Iran (IPI). These cell lines were cultured in RPMI (Roswell Park Memorial Institute, Gibco-Invitrogen, Grand Island, USA)-1640 supplemented with 10\% of fetal bovine serum (FBS, Gibco-Invitrogen, Grand Island, USA), and $1 \%$ penicillin/streptomycin (Sigma, USA) at $37{ }^{\circ} \mathrm{C}$ in a humidified atmosphere with $5 \% \mathrm{CO}_{2}$. 
Ovarian Granulosa cells (GCs) were extracted from NMRI mice 21-24 aging days (Royan Institute). After the mice sacrificed, GCs cells were extracted by a combination of enzymatic and mechanical methods (Fig. S2). GCs cells were cultured in the $\alpha$-MEM (Alpha Minimum Essential Medium Eagle, Gibco-Invitrogen, Grand Island, USA) culture medium supplemented with $10 \%$ of fetal bovine serum (FBS), and $1 \%$ penicillin/streptomycin at $37^{\circ} \mathrm{C}$ in a humidified atmosphere with $5 \% \mathrm{CO}_{2}$ and flow cytometry analysis performed to evaluated isolated cells (Fig. S7).

\section{Plasma device and characterization:}

Among the four plasma jets that were made at the start of the work, a jet with the longest plasma plume and lower temperature operated under the low inlet gas and voltage conditions was selected (Fig. S1). We used four of the plasma therapies included, direct plasma exposure contains 1\% FBS (direct 1\% FBS), direct plasma exposure contains 10\% FBS (direct 10\% FBS), PAM 1\% FBS, and PAM 10\% FBS. In the direct exposure method, we set cells in contact with CAP at different treatment durations ranging from 0 to $240 \mathrm{~s}$. Also, to prepare PAM, we exposed a fresh culture medium to the CAPJ similarly to the CAP treatment conditions. The distance between the 96 well cell culture plates and the plasma jet was kept constant at $10 \mathrm{~mm}$ during the experiment. Further details of the plasma device operation and diagnostics can be found in Supplementary Information (Figs. S5, S6 ).

\section{Cell viability assay:}

The viability of cells after treatment with drugs and plasma in conditions mentioned in the above sections was assessed using (3-(4,5-dimethylthiazol-2-yl)- 2,5-diphenyltetrazolium bromide) (MTT, Merck, Germany). $200 \mu$ l MTT solution added to each well $24 \mathrm{~h}$ after treatment and incubated for 3-4 hours. Then when MTT solution was removed, added $150 \mu 1$ DMSO (dimethyl 
sulfoxide, Merck, Germany) per well to dissolve the MTT formazan and absorbance of colored solution was measured using a microplate reader (Bio-Rad, USA) at the wavelength of $570 \mathrm{~nm}$.

\section{Combination treatments:}

Combination treatments were based on chemotherapy, CAP, and PAM treatment experiments. A2780 CP, SKOV-3, and GCs cells were seeded into a 96-well cell-culture plate. After reached $80 \%$ confluence, we performed the synergistic effect of plasma and chemotherapy drugs in three methods, first PAM $60 \mathrm{~s}, 120 \mathrm{~s}$, and CAR $20 \mu \mathrm{M}$, then PAM $60 \mathrm{~s}, 120 \mathrm{~s}$ and $0.075 \mu \mathrm{M}$ PTX, and the final step, PAM 60s, $120 \mathrm{~s}$ with CAR $20 \mu \mathrm{M}$ plus $0.075 \mu \mathrm{M}$ PTX. The therapeutic effects were evaluated using the MTT viability assay.

\section{Extracellular $\mathrm{H}_{2} \mathrm{O}_{2}, \mathrm{NO}_{2}^{-}$, and $\mathrm{NO}_{3}{ }^{-}$in culture medium:}

For the measurement of $\mathrm{H}_{2} \mathrm{O}_{2}, \mathrm{NO}_{2}{ }^{-}$, and $\mathrm{NO}_{3}{ }^{-}$in the culture medium after plasma exposure, we used a colorimetric assay. Further details of the assay can be found in Supplementary Information.

\section{Quantitative real-time reverse transcription-polymerase chain reaction (qRT-PCR):}

Total RNA was prepared $24 \mathrm{~h}$ after treatment using RNA extraction Kit (Parstous Biotechnology, Iran) per manufacturer's instruction. then cDNA was synthesized with PrimeScript 1st Strand cDNA Synthesis Kit (Parstous biotechnology, Iran). To check the presence of related mRNA, Real-Time PCR was carried out using SYBR Green PCR Master Mix in triplicate format for each gene utilizing Takara One-Step SYBR®PrimeScript ${ }^{\mathrm{TM}}$ RT-PCR Kit II (RR086A, Japan) based on the manufacturer's protocol by Applied Biosystems 7500 System. The relative expression level of each target gene was analyzed by the $2^{-\Delta \Delta C \mathrm{~T}}$ method.

\section{Hematoxylin and eosin staining:}


Hematoxylin-eosin staining was performed to the check morphological change of normal and cancer cells, $24 \mathrm{~h}$ after treatment using a light microscope (Zeist, Germany). Briefly, cells were washed 3 times with distilled water, hematoxylin (Bio-Idea, Iran) dye was added to the cells, and after five minutes the cells were again washed with distilled water, then eosin (Bio-Idea, Iran) added to cells for one minute. As a final step, we fixed the cell used alcohols $70 \%, 96 \%$, and $100 \%$ and finally observed changes of them with a microscope.

\section{Detection of apoptosis by dual acridine orange/ propidium iodide staining:}

In this study, we performed AO/PI staining to observed apoptosis and necrotic cells $24 \mathrm{~h}$ after treatment. In brief, we removed the culture medium and cells trypsinized, then Acridine orange (Bio-Idea, Iran) $(100 \mu \mathrm{g} / \mathrm{mL})$ and Propodium iodide (Bio-Idea, Iran) $(100 \mu \mathrm{g} / \mathrm{mL})(1: 1)$ added to cells. The cells were immediately moved on to slides and observed under a fluorescence microscope (Zeist, Germany) for the evaluation of the cells undergoing apoptosis or necrosis.

\section{Selectivity index calculation:}

The selectivity index corresponded to the $\mathrm{IC}_{50}$ value determined for the activity of carboplatin (CAR) and paclitaxel (PTX) on GCs cells divided by the $\mathrm{IC}_{50}$ determined for ovarian cancer cells. Our basis for specifying the selective effect was the selectivity index specified by Bézivin et al. ${ }^{49}$

\section{Statistical analysis:}

Statistical analysis was performed using Graphpad Prism 8 (GraphPad Software, CA). The results are expressed as the mean \pm standard deviation (SD) of at least three independent experiments were performed in triplicate. One-way ANOVA and Two-way ANOVA analysis of variance and Tukey's and Dunnett's post hoc multiple-comparisons tests were performed to analyze differences 
between groups. $\mathrm{P}<0.05(*), \mathrm{P}<0.01(* *), \mathrm{P}<0.001(* * *)$, indicated statistical significances compared with the control.

\section{REFERENCES:}

1. Jiang, Y.-X. et al. Ascites-derived ALDH+CD44+ tumour cell subsets endow stemness, metastasis and metabolic switch via PDK4-mediated STAT3/AKT/NF-אB/IL-8 signalling in ovarian cancer. Br. J. Cancer 11, 1-13 (2020).

2. Zhao, Y. et al. Chemotherapy exacerbates ovarian cancer cell migration and cancer stem cell-like characteristics through GLI1. Br. J. Cancer 122, 1638-1648 (2020).

3. Bauer, G., Sersenová, D., Graves, D. B. \& Machala, Z. Cold Atmospheric Plasma and Plasma-Activated Medium Trigger RONS-Based Tumor Cell Apoptosis. Sci. Rep. 9, 1-28 (2019).

4. Privat-Maldonado, A., Bengtson, C., Razzokov, J., Smits, E. \& Bogaerts, A. Modifying the tumour microenvironment: Challenges and future perspectives for anticancer plasma treatments. Cancers (Basel). 11, (2019).

5. Tornin, J. et al. Pyruvate Plays a Main Role in the Antitumoral Selectivity of Cold Atmospheric Plasma in Osteosarcoma. Sci. Rep. 9, 1-13 (2019).

6. Privat-Maldonado, A. et al. ROS from Physical Plasmas: Redox Chemistry for Biomedical Therapy. Oxid. Med. Cell. Longev. 2019, (2019).

7. Bauer, G., Sersenová, D., Graves, D. B. \& Machala, Z. Dynamics of Singlet OxygenTriggered, RONS-Based Apoptosis Induction after Treatment of Tumor Cells with Cold Atmospheric Plasma or Plasma-Activated Medium. Sci. Rep. 9, 1-34 (2019). 
8. Mitra, S. et al. Impact of ROS generated by chemical, physical, and plasma techniques on cancer attenuation. Cancers (Basel). 11, 1-31 (2019).

9. Biscop, E. et al. Influence of cell type and culture medium on determining cancer selectivity of cold atmospheric plasma treatment. Cancers (Basel). 11, (2019).

10. Dai, X., Zhang, Z., Zhang, J. \& Ostrikov, K. Dosing: The key to precision plasma oncology. Plasma Process. Polym. 1-15 (2020).

11. Lu, X. et al. Reactive species in non-equilibrium atmospheric-pressure plasmas: Generation, transport, and biological effects. Phys. Rep. 630, 1-84 (2016).

12. Keidar, M. et al. Cold plasma selectivity and the possibility of a paradigm shift in cancer therapy. Br. J. Cancer 105, 1295-1301 (2011).

13. Dai, X., Bazaka, K., Richard, D. J., Thompson, E. (Rik) W. \& Ostrikov, K. (Ken). The Emerging Role of Gas Plasma in Oncotherapy. Trends Biotechnol. 36, 1183-1198 (2018).

14. Hayashi, N., Miyamaru, Y., Aijima, R. \& Yamashita, Y. Activation of p53-Mediated Apoptosis Pathway in HSC3 Cancer Cell Irradiated by Atmospheric DBD Oxygen Plasma. IEEE Trans. Plasma Sci. 47, 1093-1099 (2019).

15. Nguyen, D. B., Mok, Y. S., Huynh, D. L., Jeong, D. K. \& Lee, W. G. Application of plasma jet to the inhibition of the proliferation of hepatic malignant cells via reactive oxygen species generation. Plasma Process. Polym. 16, (2019).

16. Lin, L., Yan, D., Gjika, E., Sherman, J. H. \& Keidar, M. Atmospheric Plasma Meets Cell: Plasma Tailoring by Living Cells. ACS Appl. Mater. Interfaces 11, 30621-30630 (2019).

17. Siu, A. et al. Differential effects of cold atmospheric plasma in the treatment of malignant 
glioma. PLoS One 10, 1-14 (2015).

18. Liu, Y. et al. Selective effects of non-thermal atmospheric plasma on triple-negative breast normal and carcinoma cells through different cell signaling pathways. Sci. Rep. 7, $1-12$ (2017).

19. Bekeschus, S. et al. Risk assessment of kINPen plasma treatment of four human pancreatic cancer cell lines with respect to metastasis. Cancers (Basel). 11, 1-19 (2019).

20. Bisag, A. et al. Plasma-activated ringer's lactate solution displays a selective cytotoxic effect on ovarian cancer cells. Cancers (Basel). 12, 1-16 (2020).

21. Tokunaga, T. et al. Plasma-stimulated medium kills TRAIL-resistant human malignant cells by promoting caspase-independent cell death via membrane potential and calcium dynamics modulation. Int. J. Oncol. 52, 697-708 (2018).

22. Hirst, A. M. et al. Low-temperature plasma treatment induces DNA damage leading to necrotic cell death in primary prostate epithelial cells. Br. J. Cancer 112, 1536-1545 (2015).

23. Guerrero-Preston, R. et al. Cold atmospheric plasma treatment selectively targets head and neck squamous cell carcinoma cells. Int. J. Mol. Med. 34, 941-946 (2014).

24. Kim, S. J. \& Chung, T. H. Cold atmospheric plasma jet-generated RONS and their selective effects on normal and carcinoma cells. Sci. Rep. 6, 1-14 (2016).

25. Gümbel, D. et al. Comparison of cold atmospheric plasma devices' efficacy on osteosarcoma and fibroblastic in vitro cell models. Anticancer Res. 37, 5407-5414 (2017).

26. Kaushik, N., Kumar, N., Kim, C. H., Kaushik, N. K. \& Choi, E. H. Dielectric barrier 
discharge plasma efficiently delivers an apoptotic response in human monocytic lymphoma. Plasma Process. Polym. 11, 1175-1187 (2014).

27. Girard, P. M. et al. Synergistic Effect of $\mathrm{H} 2 \mathrm{O} 2$ and $\mathrm{NO} 2$ in Cell Death Induced by Cold Atmospheric He Plasma. Sci. Rep. 6, 1-17 (2016).

28. Van Boxem, W. et al. Anti-cancer capacity of plasma-treated PBS: effect of chemical composition on cancer cell cytotoxicity. Sci. Rep. 7, 16478 (2017).

29. Yan, D. et al. The Cell Activation Phenomena in the Cold Atmospheric Plasma Cancer Treatment. Sci. Rep. 8, 1-10 (2018).

30. Nakamura, K., Peng, Y., Utsumi, F., Tanaka, H. \& Mizuno, M. Novel Intraperitoneal Treatment With Non-Thermal Plasma- Activated Medium Inhibits Metastatic Potential of Ovarian Cancer Cells. Sci. Rep. 1-14 (2017).

31. Duan, J., Lu, X. \& He, G. The selective effect of plasma activated medium in an in vitro co-culture of liver cancer and normal cells. J. Appl. Phys. 121, (2017).

32. Yan, D. et al. Controlling plasma stimulated media in cancer treatment application. Appl. Phys. Lett. 105, 224101 (2014).

33. Kurake, N. et al. Cell survival of glioblastoma grown in medium containing hydrogen peroxide and/or nitrite, or in plasma-activated medium. Arch. Biochem. Biophys. 605, 102-108 (2016).

34. Vilema-Enríquez, G., Arroyo, A., Grijalva, M., Amador-Zafra, R. I. \& Camacho, J. Molecular and cellular effects of hydrogen peroxide on human lung cancer cells: Potential therapeutic implications. Oxid. Med. Cell. Longev. 2016, (2016). 
35. López-Lázaro, M. Dual role of hydrogen peroxide in cancer: Possible relevance to cancer chemoprevention and therapy. Cancer Lett. 252, 1-8 (2007).

36. Bauer, G. The synergistic effect between hydrogen peroxide and nitrite, two long-lived molecular species from cold atmospheric plasma, triggers tumor cells to induce their own cell death. Redox Biol. 26, 101291 (2019).

37. Vermeylen, S. et al. Cold atmospheric plasma treatment of melanoma and glioblastoma cancer cells. Plasma Process. Polym. 13, 1195-1205 (2016).

38. Fraser, M., Chan, S. L., Chan, S. S. L., Fiscus, R. R. \& Tsang, B. K. Regulation of p53 and suppression of apoptosis by the soluble guanylyl cyclase/cGMP pathway in human ovarian cancer cells. Oncogene 25, 2203-2212 (2006).

39. Chen, T., Li, M., Zhang, R. \& Wang, H. Dihydroartemisinin induces apoptosis and sensitizes human ovarian cancer cells to carboplatin therapy. J. Cell. Mol. Med. 13, 13581370 (2009).

40. Luo, H., Rankin, G. O., Li, Z., DePriest, L. \& Chen, Y. C. Kaempferol induces apoptosis in ovarian cancer cells through activating p53 in the intrinsic pathway. Food Chem. 128, 513-519 (2011).

41. Ishaq, M., Evans, M. \& Ostrikov, K. Effect of atmospheric gas plasmas on cancer cell signaling. Int. J. Cancer 134, 1517-1528 (2014).

42. Saadati, F. et al. Comparison of Direct and Indirect cold atmospheric-pressure plasma methods in the B16F10 melanoma cancer cells treatment. Sci. Rep. 8, 1-15 (2018).

43. Somwar, R. et al. Superoxide dismutase 1 (SOD1) is a target for a small molecule 
identified in a screen for inhibitors of the growth of lung adenocarcinoma cell lines. Proc. Natl. Acad. Sci. 108, 16375-16380 (2011).

44. Glasauer, A., Sena, L. A., Diebold, L. P., Mazar, A. P. \& Chandel, N. S. Targeting SOD1 reduces experimental non-small-cell lung cancer. J. Clin. Invest. 124, 117-128 (2014).

45. Köritzer, J. et al. Restoration of Sensitivity in Chemo - Resistant Glioma Cells by Cold Atmospheric Plasma. PLoS One 8, e64498 (2013).

46. Ishaq, M., Han, Z. J., Kumar, S., Evans, M. D. M. \& Ostrikov, K. (Ken). AtmosphericPressure Plasma- and TRAIL-Induced Apoptosis in TRAIL-Resistant Colorectal Cancer Cells. Plasma Process. Polym. 12, 574-582 (2015).

47. Kelland, L. The resurgence of platinum-based cancer chemotherapy. Nat. Rev. Cancer 7, 573-584 (2007).

48. Bauer, G. Central signaling elements of intercellular reactive oxygen/nitrogen speciesdependent induction of apoptosis in malignant cells. Anticancer Res. 37, 499-514 (2017).

49. Bézivin, C., Tomasi, S., Lohézic-Le Dévéhat, F. \& Boustie, J. Cytotoxic activity of some lichen extracts on murine and human cancer cell lines. Phytomedicine 10, 499-503 (2003).

\section{Acknowledgments}

M.R. acknowledge partial support from the Biotechnology Development Council of Iranian VicePresidency Science and Technology (Grant No. 1131591). 


\section{Author contributions}

M.R. designed the plasma device, biological experiments, and performed the experiments and prepared the initial version of the manuscript. H.M. and K.H. supervised plasma related studies and contributed to data anlysis and manuscript structuring and writing. E.A. supervised biological studies. K.O. contributed to data interpretation and manuscript structuring and improvement. E.R. contributed to review and improve the final version of the manuscript. All authors read and approved the final version of the paper.

Competing interests The authors declare no competing interests.

\section{Data Availability}

The data used to support the findings of this study are available from the corresponding author upon reasonable request.

\section{Additional information}

Supplementary information is available for this paper at

Correspondence and requests for materials should be addressed to M.R.

Consent to publish Not applicable. 
Figures

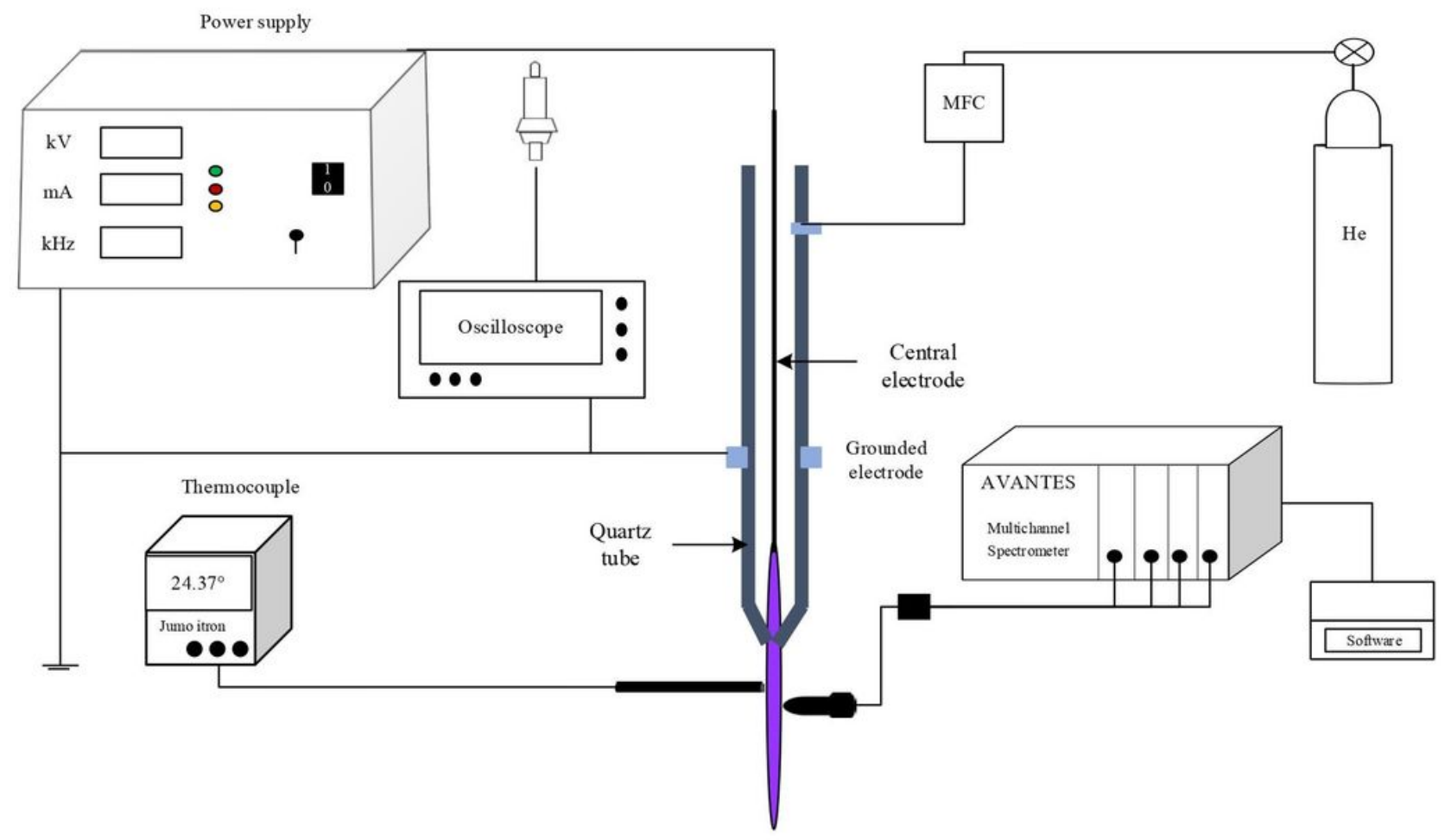

Figure 1

Schematic of the experimental setup 

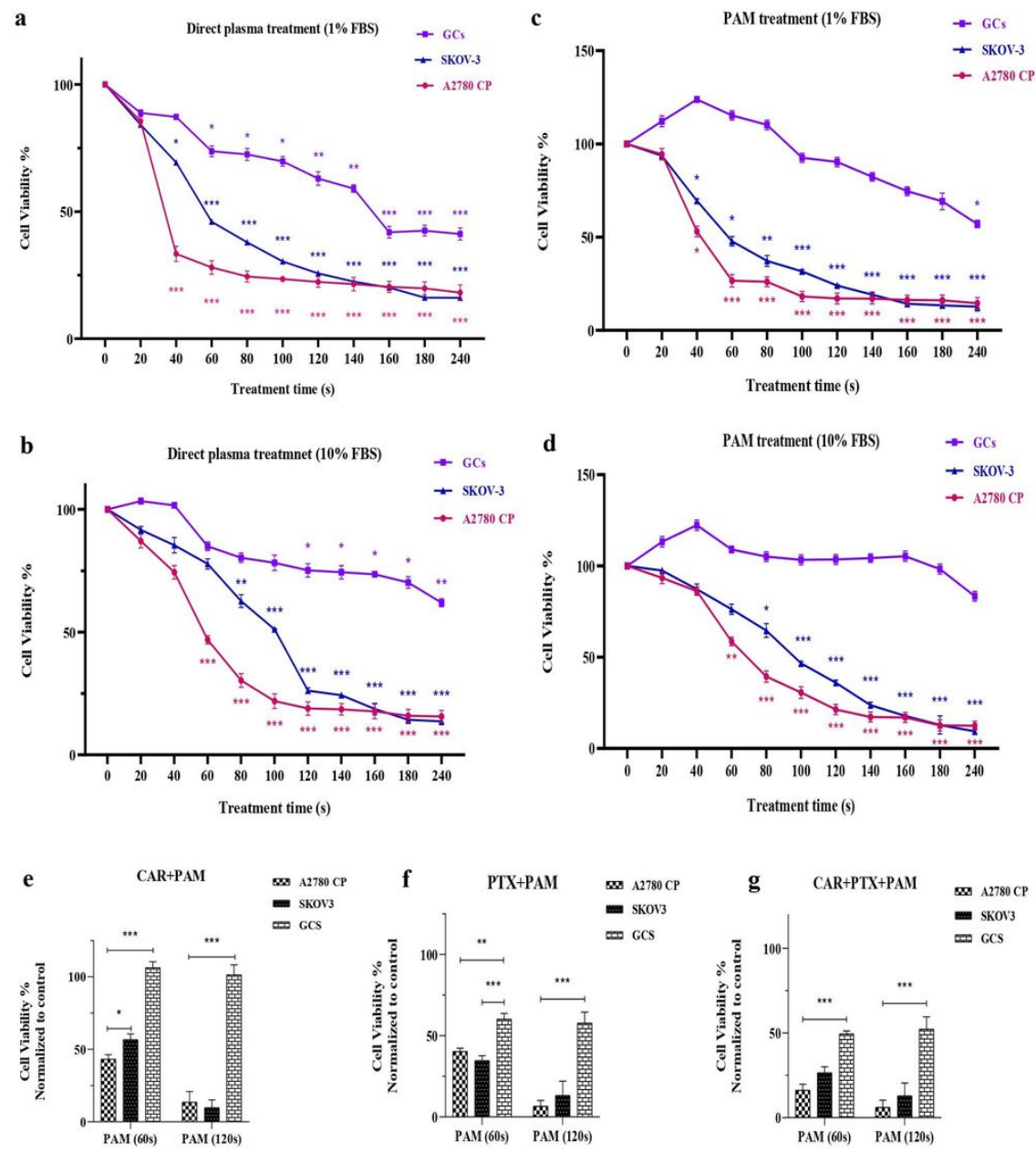

\section{Figure 2}

Viability of GCs, SKOV-3, and A2780 CP cells treated with CAP, PAM, and combination of PAM with chemotherapy drugs as measured by the cell viability assay. (a) Direct plasma treatment (1\% FBS). (b) Direct plasma treatment (10\% FBS). (c) PAM treatment (1\% FBS). (d) PAM treatment (10\% FBS). (e) PAM in combination with $0.075 \mu \mathrm{M}$ PTX and $20 \mu \mathrm{M}$ CAR. (f) PAM in combination with $0.075 \mu \mathrm{M}$ PTX. (g) PAM in combination with $20 \mu \mathrm{M}$ CAR. The percentages of surviving cells from each cell were calculated relative to controls. All experiments have replicated a minimum of three times. Data are presented as means \pm S.D. $\left({ }^{*} p<0.05,{ }^{* \star} p<0.01,{ }^{* \star} p<0.001\right.$ versus control). 


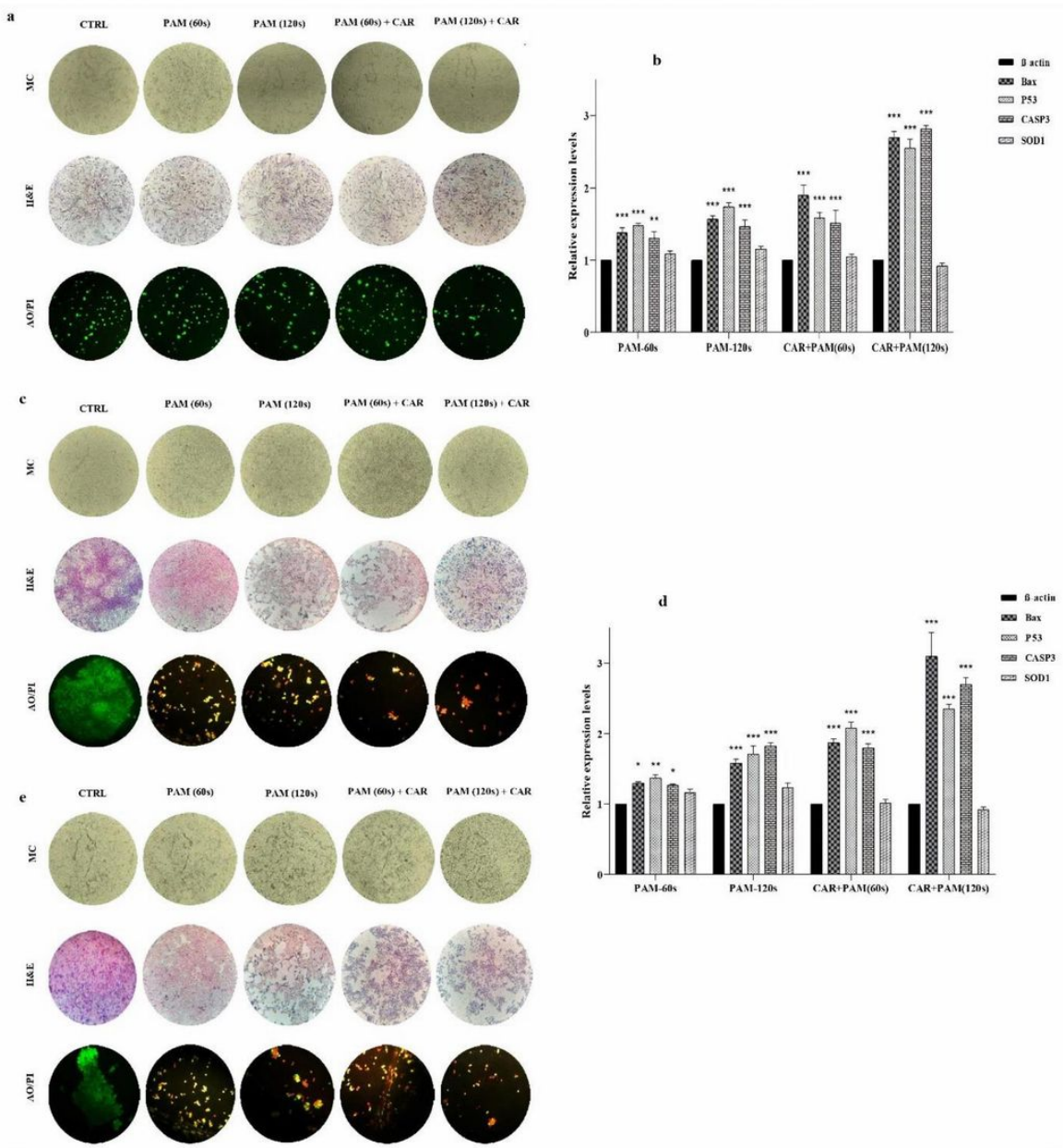

\section{Figure 3}

(a) Morphological change, Hematoxylin and Eosin, and acridine orange/propidium iodide staining of GCS cells. (b) RT-PCR quantitation of mRNA levels of Bax, P53, Caspase 3, and SOD1 in A2780 CP cells (c) Morphological change, Hematoxylin and Eosin, and acridine orange/propidium iodide staining of A2780 CP cells, (d) RT-PCR quantitation of mRNA levels of Bax, P53, Caspase 3, and SOD1 in SKOV3 cells. (e) Morphological change, Hematoxylin and Eosin, and acridine orange/propidium iodide 10 staining of SKOV-3 cells. actin beta ( $\beta$-actin) was used as control. Data are the mean of at least three different experiments. Data are presented as means \pm S.D. $\left({ }^{\star} p<0.05,{ }^{*} \mathrm{p}<0.01, * \star * p<0.001\right.$ versus control). as expected of MTT and other tests, a strong increase of both Bax and $p 53$ expression compared to control was measured $(p<0.001)$. Further, the caspase-3 mRNA expression had a noticeable changes ( $<0.01$ ), $(p<0.001),(p<0.001),(p<0.001)$ at PAM (60s), PAM (120s), CAR with PAM (60s), and CAR with PAM (120s), respectively (Fig. 3.b). Furthermore, for SKOV-3 cell lines, in comparison with untreated cells, we detected the overexpression ( $p<0.001)$ for $p 53$, Bax, and caspase-3 genes at PAM (120s), CAR with PAM (60s), and CAR with PAM (120s), respectively. While in PAM (60s) expression of $p 53$, Bax, and caspase-3 genes were $(p<0.01)$, ( $<<0.05)$, and ( $<<0.05)$, respectively (Fig. 3.d). Another gene that was evaluated in this study was SOD1, which had a non-significant change in comparison to non-treatment for two cell lines in all treatments (Figure 3.b,d). 


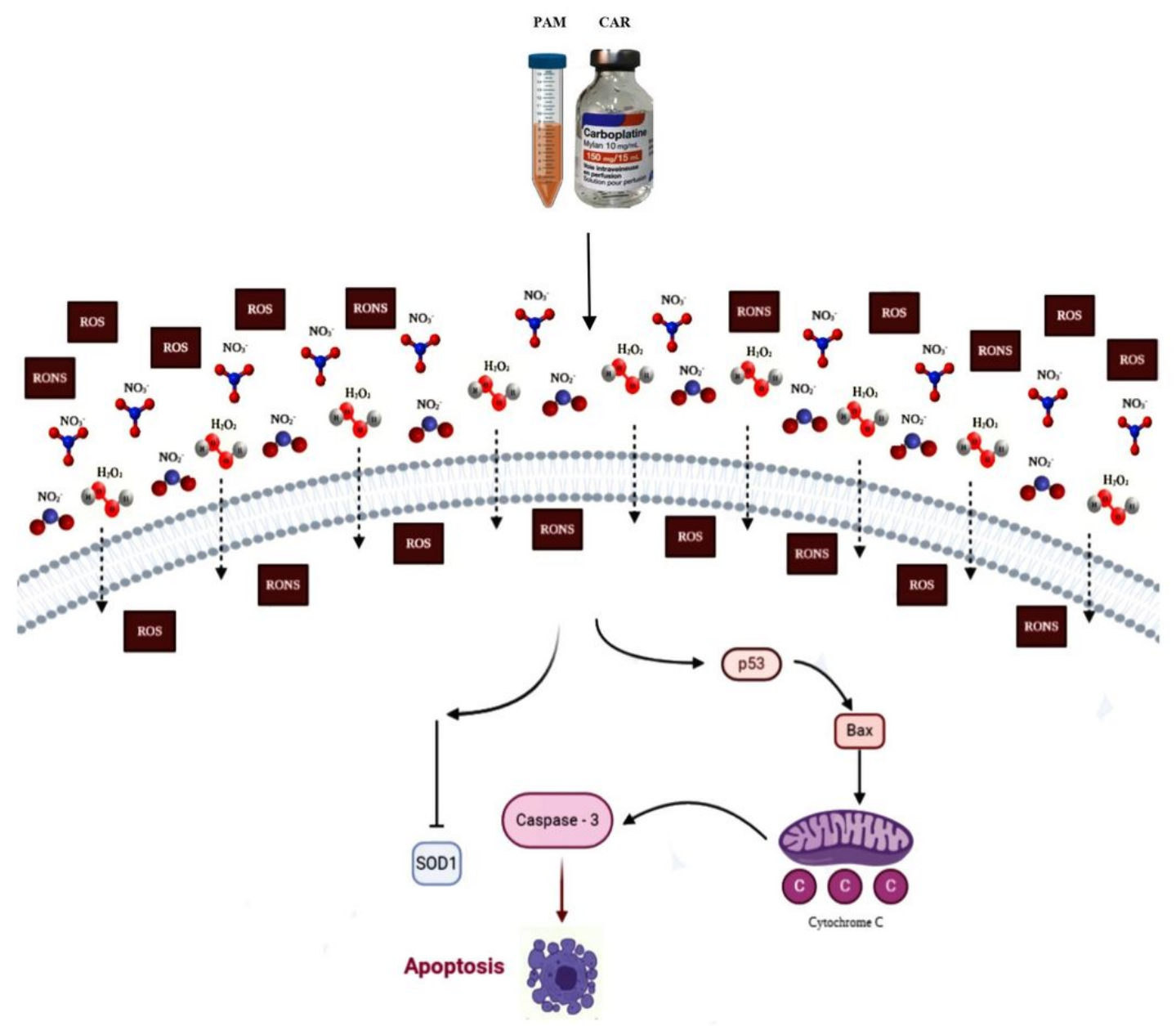

Figure 4

Molecular mechanism of inhibition of the SOD1 and mitochondrial related intrinsic apoptosis inducing by PAM and CAR

\section{Supplementary Files}

This is a list of supplementary files associated with this preprint. Click to download.

- SupplementaryinformationPlasmaactivatedmediuminducesapoptosisinchemotherapyresistantovariancancercellshighselectivityandsynergywithcarboplati 